\title{
USO DO ÓLEO DE SOJA PRÉ-AQUECIDO EM UM MOTOR ESTACIONÁRIO DE CICLO DIESEL
}

\author{
Elton Fialho dos Reis ${ }^{1}$, Daniel Max Leonídio², Sanchez de Castro Lacerda ${ }^{3}$, Itamar Rosa Teixeira ${ }^{4}$
}

\section{RESUMO}

A produção, avaliação, melhorias e uso de combustíveis renováveis, como o óleo vegetal compõe um dos pilares da sustentabilidade ambiental. Objetivou-se avaliar a emissão de gases e o consumo horário da utilização de óleo vegetal de soja, em diferentes temperaturas e cargas aplicadas, em motor gerador estacionário de ciclo diesel de $2 \mathrm{kVA}$. O delineamento experimental utilizado foi inteiramente casualizado no esquema fatorial $5 \times 5$, sendo utilizadas cinco temperaturas do óleo de soja $\left(25^{\circ} \mathrm{C}, 60^{\circ} \mathrm{C}, 90^{\circ} \mathrm{C}, 120^{\circ} \mathrm{C}\right.$ e $\left.150^{\circ} \mathrm{C}\right)$, com cinco cargas aplicadas ao gerador $(0,500$, $1000,1500$ e $2000 \mathrm{~W})$, com três repetições. Foram determinadas as emissões de oxigênio $\left(\mathrm{O}_{2}\right)$, dióxido de carbono $\left(\mathrm{CO}_{2}\right)$, óxidos de nitrogênio $\left(\mathrm{NO}_{x}\right)$, óxidos de enxofre $\left(\mathrm{SO}_{2}\right)$ e monóxido de carbono $(\mathrm{CO})$, e o consumo horário do motor gerador. A viscosidade reduziu com o aquecimento do óleo vegetal de soja e o seu aquecimento próximo aos $90^{\circ} \mathrm{C}$ promoveu os melhores índices de emissão de gases. A carga de demandada de $1100 \mathrm{~W}$ apresentou valor máximo de emissão de $\mathrm{NO}_{x}$ e mínimo nas emissões de $\mathrm{CO}$, já as emissões de $\mathrm{SO}_{2}$ aumentaram com o incremento da carga demandada. O consumo de combustível foi incrementado com o aquecimento do óleo de soja e o aumento da carga demandada.

Palavras-chave: aquecimento do óleo, consumo combustível, gases poluentes, grupo gerador.

\section{ABSTRACT \\ USE OF PREHEATED SOYBEAN OIL IN A STATIONARY DIESEL CYCLE MOTOR}

Production, evaluation, improvement and use of renewable fuels, such as vegetable oil, make up one of the pillars of sustainability. The objective herein was to evaluate the emission of gaseous and hourly consumption when using soy vegetable oil at different vegetable oil temperatures and applied loads, in a 2 KVA stationary diesel-cycle generator. The experimental design was completely randomized in a $5 \times 5$ factorial scheme, using five soybean oil temperatures $\left(25^{\circ} \mathrm{C}, 60^{\circ} \mathrm{C}, 90^{\circ} \mathrm{C}, 120^{\circ} \mathrm{C}\right.$ and $\left.150^{\circ} \mathrm{C}\right)$ with five loads applied to the generator $(0,500,1000,1500$ and 2000 watts) with three replications. We determined the emission of oxygen $(\mathrm{O} 2)$, carbon dioxide (CO2), nitrogen oxides (NOx), sulfur oxides (SO2) and carbon monoxide (CO), as well as the hourly consumption of the motor-generator. Viscosity was reduced by heating the soy vegetable oil. Heating the vegetable soybean oil to $90^{\circ} \mathrm{C}$ promoted the best gas emission rates. A demand load of 110 Watts presented the maximum value of $\mathrm{NOx}$ emissions and minimal emissions of $\mathrm{CO}$, however $\mathrm{SO} 2$ emissions increased with increase in the demand load. The fuel consumption was increased by heating the soybean oil and increasing the demand load.

Keywords: fuel consumption, heating oil, greenhouse gases, genset.

Recebido para publicação em 20/06/2014. Aprovado em 29/06/2015.

1 - Engenheiro Agrícola, Prof. Doutor, UEG, Campus Anápolis - GO. fialhoreis@ueg.br;

2 - Engenheiro Agrícola, UEG, Campus Anápolis - GO. daniel_max1@hotmail.com;

3 - Engenheiro Agrícola, Mestre Engenharia Agrícola UEG, Campus Anápolis-GO. sanchezlacerda@hotmail.com;

4 - Engenheiro Agrônomo, Prof. Doutor, UEG, Campus Anápolis - GO. itamar.texeira@ueg.br. 


\section{INTRODUÇÃO}

A demanda por combustíveis de fontes renováveis cresce com a valorização nos preços do petróleo e da vantagem brasileira na produção desses combustíveis. O Brasil é um dos maiores produtores e consumidores de biodiesel do mundo, com produção anual, em 2012, de 2,72 bilhões de litros e capacidade instalada de cerca de 20,57 milhões de litros por dia em relação ao mesmo ano (ANP, 2013).

O biodiesel é produzido a partir de óleos vegetais ou gordura animal. Diversas espécies vegetais presentes no Brasil podem ser usadas na produção do mesmo, como a soja, dendê, girassol, babaçu, amendoim, mamona e pinhão-manso (TOMAZZONI et al., 2013).

A forma in naturado do óleo vegetal pode ser alternativaviável, desdequesejamaplicadastécnicas adequadas para melhorar a injeção do combustível no motor ou utilizando-se misturas com óleo diesel, em proporções que deverão ser estudadas (INOUE, 2008). A Resolução ANP n 7/2008, apresentam-se as especificações mínimas para o uso de biodiesel, na qual fica proibida a adição do óleo vegetal in natura ao diesel, por apresentar características físico-químicas diferentes do diesel (ANP, 2009).

O pré-aquecimento do óleo vegetal foi estudado por Büttner (1994), a fim de reduzir sua viscosidade, característica esta que foi tratada como um fator limitante para sua utilização em motores diesel. As técnicas frequentemente utilizadas para alimentar um motor diesel com óleo vegetal, em nível de até $100 \%$, são o aquecimento e a alternância de combustível, conforme o mesmo autor.

$\mathrm{O}$ aquecimento pode ser feito por meio de sistemas instalados nos reservatórios, utilizando como fonte de calor a resistência elétrica, cujo sistema é comercializado em alguns países da Europa, ou utilizando os fluidos do sistema de arrefecimento e dos gases de escape (INOUE, 2008).

O pré-aquecimento do uso de óleo de soja modifica os fluxos de admissão de combustível pela bomba injetora e de retorno, podendo resultar em desgastes do sistema de injeção, e o aquecimento próximo aos $120^{\circ} \mathrm{C}$ promove característica de viscosidade ao óleo de soja similar ao do petrodiesel (MARTINI et al., 2012).
O efeito do uso de óleo bruto de girassol em um motor MWM D229.3 foi estudado por Mazieiro et al. (2007), observando redução de desempenho mecânico e avarias no sistema, provocadas por contaminação e formação de incrustações no interior do motor. Rabelo et al. (2011), utilizando óleo usado em frituras de alimentos, obtiveram maior potência, torque e mesmo consumo específico que o diesel metropolitano para rotações inferiores a $2200 \mathrm{rpm}$, e acima de $1900 \mathrm{rpm}$, o óleo de frituras mostrou-se melhor, também, no que se refere ao rendimento térmico.

Machado (2003), utilizando um motor MWM modelo 229, com injeção direta e de quatro tempos, verificou que a viscosidade elevada do óleo de palma resultou em atomização pobre, depósitos de carbono, obstrução de linhas de combustível e dificuldades na partida em temperaturas baixas. Porém, quando aquecido a $100{ }^{\circ} \mathrm{C}$, apresentou viscosidade mais baixa, melhor combustão e menor formação de depósitos. Já Schlosser et al. (2007), realizando ensaios em motores agrícolas com misturas pré-aquecidas de óleo de soja cru e diesel, encontraram que o aquecimento realizado a $68^{\circ} \mathrm{C}$ apresentaram sempre os melhores valores para torque, potência e consumo específico de combustível do que a $57^{\circ} \mathrm{C}$. Uma mistura composta por $70 \%$ de óleo de soja e $30 \%$ de óleo diesel, aquecida a $68^{\circ} \mathrm{C}$, apresentou os melhores resultados.

Portanto, neste trabalho, objetivou-se avaliar a emissão de gases e o consumo horário com o uso de óleo vegetal de soja pré-aquecido antes da bomba injetora com cargas aplicadas, em motor gerador estacionário de ciclo diesel de 2 kVA.

\section{MATERIAL E MÉTODOS}

$\mathrm{O}$ experimento foi conduzido na área externa do laboratório de Protótipos de Máquinas Agrícolas, utilizando um delineamento inteiramente casualizado, no esquema fatorial $5 \times 5$, utilizando-se cinco temperaturas do óleo de soja $\left(25^{\circ} \mathrm{C}, 60^{\circ} \mathrm{C}, 90^{\circ} \mathrm{C}, 120^{\circ} \mathrm{C}, 150^{\circ} \mathrm{C}\right)$, com cinco cargas aplicadas pelo gerador $(0,500$, $1000,1500,2000 \mathrm{~W})$, com três repetições.

Para o aquecimento do óleo utilizou-se uma chapa aquecedora da marca Fisatom, Modelo $752 \mathrm{~A}$, depois de aquecido o óleo foi armazenado em um béquer de $1000 \mathrm{ml}$ com a temperatura 
monitorada por um termômetro graduado de $200^{\circ} \mathrm{C}$.

Foi utilizado um motor gerador de ciclo Diesel com motor mono cilindro 4 tempos, de $5 \mathrm{hp}$ de potência, com injeção direta, marca BRANCO, modelo BD-2500 CF, como mostrado na Figura 1(A), com capacidade nominal de 2,0 kVA.

De acordo com recomendações do fabricante ao se dar início ao funcionamento do motor gerador é necessário deixá-lo ligado em funcionamento por cerca de cinco minutos, sem carga, para estabilizar a temperatura do óleo do cárter. Dessa forma, antes de serem iniciados os ensaios e em cada sequência de ensaios, seguiu-se essa recomendação para que a temperatura de funcionamento do motor não influenciasse nos resultados obtidos.

Quando necessária a troca de combustível, o conjunto permaneceu ligado com o combustível na nova temperatura consumindo a quantidade de $50 \mathrm{~mL}$, antes de quantificar as variáveis, adaptando o sistema de alimentação do motor a nova temperatura do óleo vegetal.

O sistema utilizado para simular as diferentes demandas de cargas elétricas do motor, foi constituído de uma plataforma com suporte para 10 lâmpadas com carga variando de $100 \mathrm{~W}, 200 \mathrm{~W}$ e $250 \mathrm{~W}$, conforme Figura 1(B), exigindo uma potência de $2000 \mathrm{~W}$ quando todas as lâmpadas foram ligadas. $O$ conjunto de lâmpadas, associadas de diferentes formas, possibilitou as exigências de diferentes demandas de carga do motor gerador, sendo elas: 500W, $1000 \mathrm{~W}, 1500 \mathrm{~W}, 2000 \mathrm{~W}$ e sem carga (desligado).

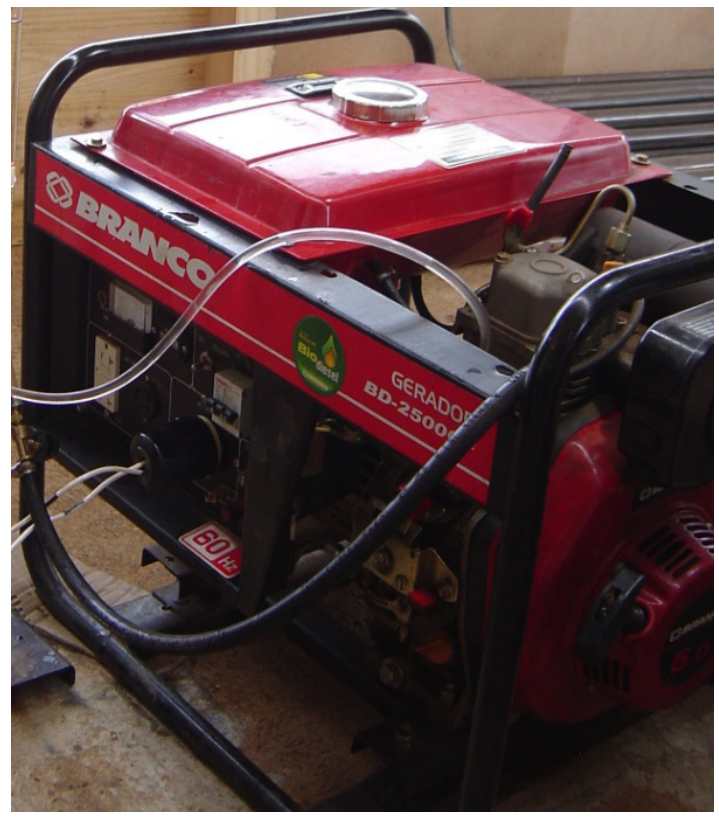

(A)

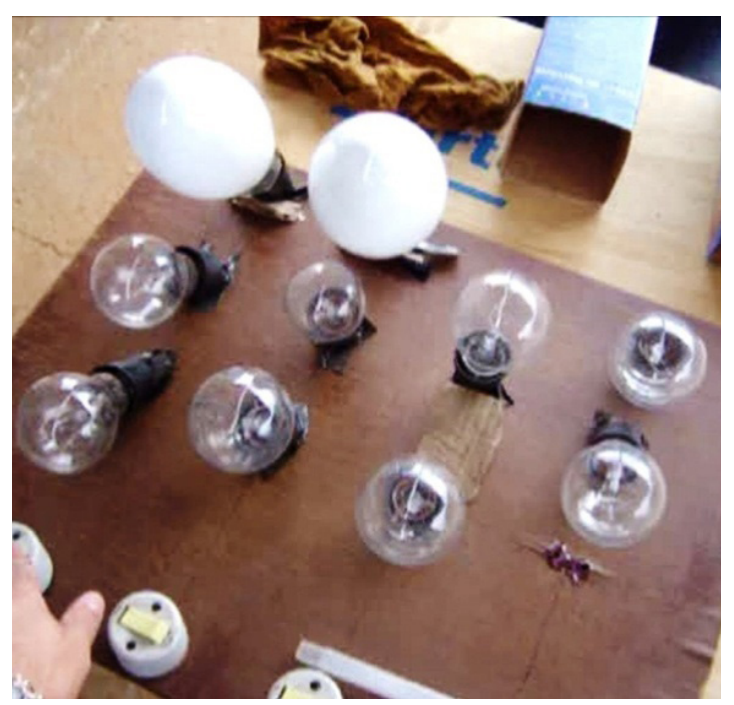

(B)

Figura 1. (A) Motor gerador de ciclo diesel modelo BD-2500 CF; (B) Conjunto de lâmpadas associadas para demanda de carga do motor gerador.

As propriedades físico-químicas do óleo de soja foram determinadas no laboratório de Enzimologia da Universidade Estadual de Goiás, em AnápolisGO, onde foram determinados a massa específica $\rho$ $\left(\mathrm{g} \mathrm{cm}^{-3}\right)$ a $20^{\circ} \mathrm{C}$ e viscosidade cinemática $v(\mathrm{cP})$ de $20^{\circ} \mathrm{C}$ a $93^{\circ} \mathrm{C}$. A determinação da massa específica foi calculada conforme Equação 1, utilizando método do picnômetro, sendo a massa aferida por uma balança analítica com precisão de $0,01 \mathrm{~g}$.

$\rho=\frac{\mathrm{m}}{\mathrm{V}}$

em que,

$\rho=$ Massa especifica $\left(\mathrm{g} \mathrm{cm}^{-3}\right)$;

$\mathrm{m}=$ Massa $(\mathrm{g})$; e

$\mathrm{V}=$ Volume $\left(\mathrm{cm}^{3}\right)$

A determinação da viscosidade cinemática foi por meio de um viscosímetro digital, da marca Brookfield, modelo DV-II + Pro, com faixa de temperatura da análise pré-estabelecida de acordo com as especificações recomendadas pelo fabricante do aparelho. O tratamento dos dados experimentais da viscosidade foi realizado utilizando o programa OriginPro 8.0. 
O consumo de combustível para as diferentes temperaturas avaliadas foi obtido por meio de um medidor volumétrico, como descrito por Barbosa et al. (2008), constituído por uma bureta graduada acoplada ao bico injetor por meio de uma mangueira, isolando o tanque de combustível.

Assim, o consumo de combustível foi determinado pelo tempo necessário para o consumo de $30 \mathrm{~mL}$, limite pré-estabelecido para o ensaio. $\mathrm{O}$ calculo do consumo horário foi realizado com base na equação2, descrita por Mialhe (1996).

$\mathrm{Ch}=\frac{\mathrm{Vc} * 3,6}{\mathrm{~T}}$

em que,

$\mathrm{Ch}=$ Consumo horário $\left(\mathrm{L} \mathrm{h}^{-1}\right)$;

$\mathrm{Vc}=$ Volume consumido $(\mathrm{mL}) ; \mathrm{e}$

$\mathrm{T}=$ Tempo de uso (s).

Os gases avaliados foram os níveis de emissões de monóxido de carbono (CO), oxigênio $\left(\mathrm{O}_{2}\right)$, dióxido de carbono $\left(\mathrm{CO}_{2}\right)$, óxidos de enxofre $\left(\mathrm{SO}_{2}\right)$ e óxidos de nitrogênio totais $\left(\mathrm{NO}_{\mathrm{x}}\right)$, formados em função da carga de trabalho e da temperatura do óleo vegetal depois da combustão.

Para a medição dos níveis de gases emitidos pelo motor foi utilizado um monitor ambiental de combustão e de emissão de gases da marca KANE, modelo 940 portátil, acoplado ao sistema de exaustão do motor gerador. $\mathrm{O}$ equipamento permitiu a aquisição dos dados conseguindo analisar simultaneamente cinco parâmetros $\left(\mathrm{O}_{2}\right.$, $\mathrm{CO}, \mathrm{CO}_{2}, \mathrm{NO}_{\mathrm{x}}, \mathrm{SO}_{2}$ ), sendo possível verificar a emissão dos gases poluentes provenientes da combustão.

Os dados obtidos foram submetidos à análise de variância pelo teste $\mathrm{F}$, a $5 \%$ de probabilidade pelo software estatístico SISVAR 5.3 (FERREIRA, 2011) e, quando significativos,foram analisados por meio de análise de regressão, sendo utilizado para a realização das análises o pacote estatístico Statistica $7.0^{\circledR}$ (STATSOFT, 2005).

\section{RESULTADOS E DISCUSSÃO}

O óleo vegetal apresentou densidade média de
$0,891 \mathrm{~g} \mathrm{~cm}^{-3}$ na temperatura de $20^{\circ} \mathrm{C}$. A redução da viscosidade com o aumento da temperatura (Figura 2) ocorreu devido à redução da resistência interna ao escoamento do óleo que, por se tratar de um fluído newtoniano, facilita o escoamento e apresenta menor viscosidade. Resultados corroboram com Inoue (2008) que, ao analisar a viscosidade do óleo vegetal de soja, milho e girassol, constatou que a maior redução da viscosidade dos óleos vegetais foi verificada entre 60 e $90^{\circ} \mathrm{C}$ e que, quanto maior a temperatura aplicada, menor foi a variação na redução da viscosidade. A viscosidade é uma característica limitante para a utilização de óleo vegetais crus em motores diesel, conforme Büttner (1994), que sugeriu o pré-aquecimento afim reduzir a viscosidade. Pimentel e Belchior (2002), ao conduzirem um trabalho para avaliação do potencial de óleo de dendê in natura como combustível, afirmaram que a utilização do óleo vegetal em temperatura ambiente provoca danos ao motor devido à alta viscosidade verificada sob essa temperatura.

De acordo com a análise de variância (Quadro 1), os resultados permitiram verificar que o oxigênio $\left(\mathrm{O}_{2}\right)$, dióxido de carbono $\left(\mathrm{CO}_{2}\right)$, óxidos de nitrogênio $\left(\mathrm{NO}_{\mathrm{x}}\right)$, dióxido de enxofre $\left(\mathrm{SO}_{2}\right)$ e monóxido de carbono (CO) variaram significativamente com o aumento da temperatura do óleo vegetal, já os óxidos de nitrogênio $\left(\mathrm{NO}_{\mathrm{x}}\right)$, dióxido de enxofre $\left(\mathrm{SO}_{2}\right)$ e monóxido de carbono (CO) apresentaram efeito significativo com o aumento das cargas aplicadas, quando analisados isoladamente, respectivamente. Para o consumo de combustível, a interação entre as diferentes temperaturas do óleo vegetal cru e as cargas aplicadas apresentou efeito significativo, conforme hipótese apresentada para a pesquisa.

Observou-se que, com o aumento da temperatura do óleo vegetal, as emissões de $\mathrm{CO}$ reduziram (Figura 3), conferindo maior eficiência na combustão, tendo em vista que o CO é produto de combustão incompleta. Já os níveis de oxigênio apresentaram uma elevação com o aumento da temperatura. De acordo com Correa et al. (2008), os níveis de $\mathrm{O}_{2}$ se elevaram devido a melhor queima de combustível, isso devido os combustíveis de origem vegetal apresentarem 


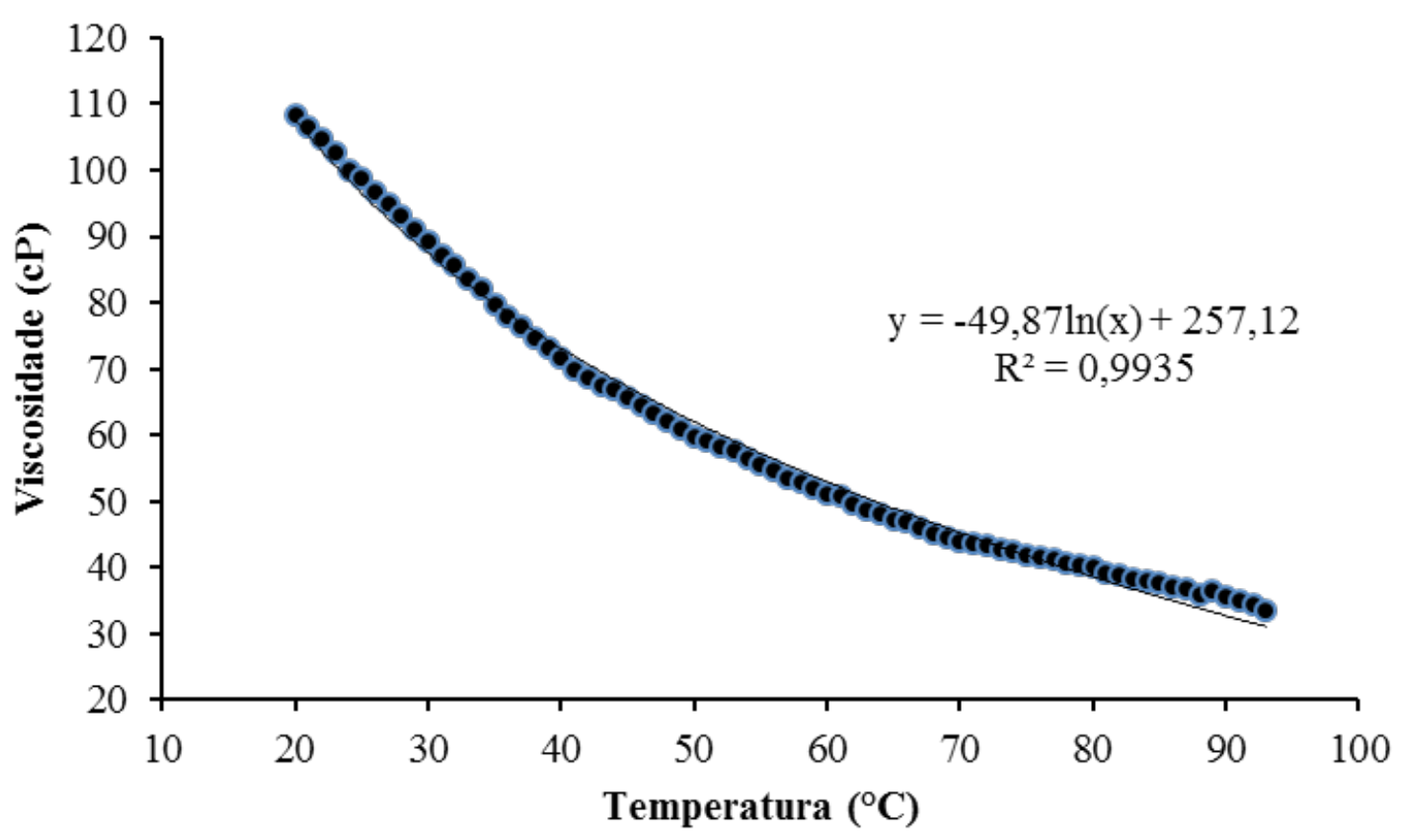

Figura 2. Variação da viscosidade em função da temperatura do óleo vegetal.

Quadro 1. Resumo da análise de variância das variáveis expresso pelo quadrado médio: emissão de oxigênio $\left(\mathrm{O}_{2}\right)$, dióxido de carbono $\left(\mathrm{CO}_{2}\right)$, óxidos de nitrogênio $\left(\mathrm{NO}_{\mathrm{x}}\right)$, óxidos de enxofre $\left(\mathrm{SO}_{2}\right)$, monóxido de carbono $(\mathrm{CO})$ e consumo horário de combustível.

\begin{tabular}{lccccccc}
\hline & GL & \multicolumn{7}{c}{$\mathbf{Q M}$} \\
\cline { 3 - 7 } & & $\mathbf{O}_{2}$ & $\mathbf{C O}_{2}$ & $\mathbf{N O}_{\mathbf{x}}$ & $\mathbf{S O}_{2}$ & $\mathbf{C O}$ & Consumo \\
\hline Temperatura & 4 & $23,387^{*}$ & $1,768^{*}$ & $988,72^{*}$ & $43,587^{*}$ & $46379,713^{*}$ & $0,0158^{*}$ \\
Carga & 4 & 0,287 & 0,033 & $386,753^{*}$ & $13,22^{*}$ & $91125,713^{*}$ & $0,817^{*}$ \\
Temp. x Carga & 16 & 0,32 & 0,02 & 71,82 & 5,762 & 2795,763 & $0,001^{*}$ \\
Resíduo & 50 & 0,573 & 0,08 & 64,987 & 5,133 & 1512,253 & 0,0003 \\
\hline Total & 74 & & & & & \\
\hline
\end{tabular}

*Significativo pelo teste $\mathrm{F}$, a $5 \%$ de probabilidade.

várias cadeias oxigenadas. Segundo Grabosky e Mccormick (1998), com maior produção de $\mathrm{O}_{2}$ ocorre melhor eficiência de combustão, ajudando assim, a redução na emissão de $\mathrm{CO}$.

Os maiores valores de $\mathrm{CO}, \mathrm{CO}_{2}, \mathrm{NO}_{\mathrm{x}}$ e $\mathrm{SO}_{2}$, foram encontrados à temperatura ambiente (Figura 3), segundo Milhor (2002), a concentração de CO no cilindro é alta durante a combustão, porém, durante o tempo de expansão uma parte é oxidada, formando $\mathrm{CO}_{2}$, justificando assim as maiores porcentagens encontradas. Os resultados encontrados para o $\mathrm{CO}_{2}$ mostraram que os menores índices foram encontrados próximos aos $113^{\circ} \mathrm{C}$ (Figura 3), fato este que justifica também os menores valores de $\mathrm{CO}$. Nota-se que houve redução significativa nas emissões de dióxido de enxofre, 


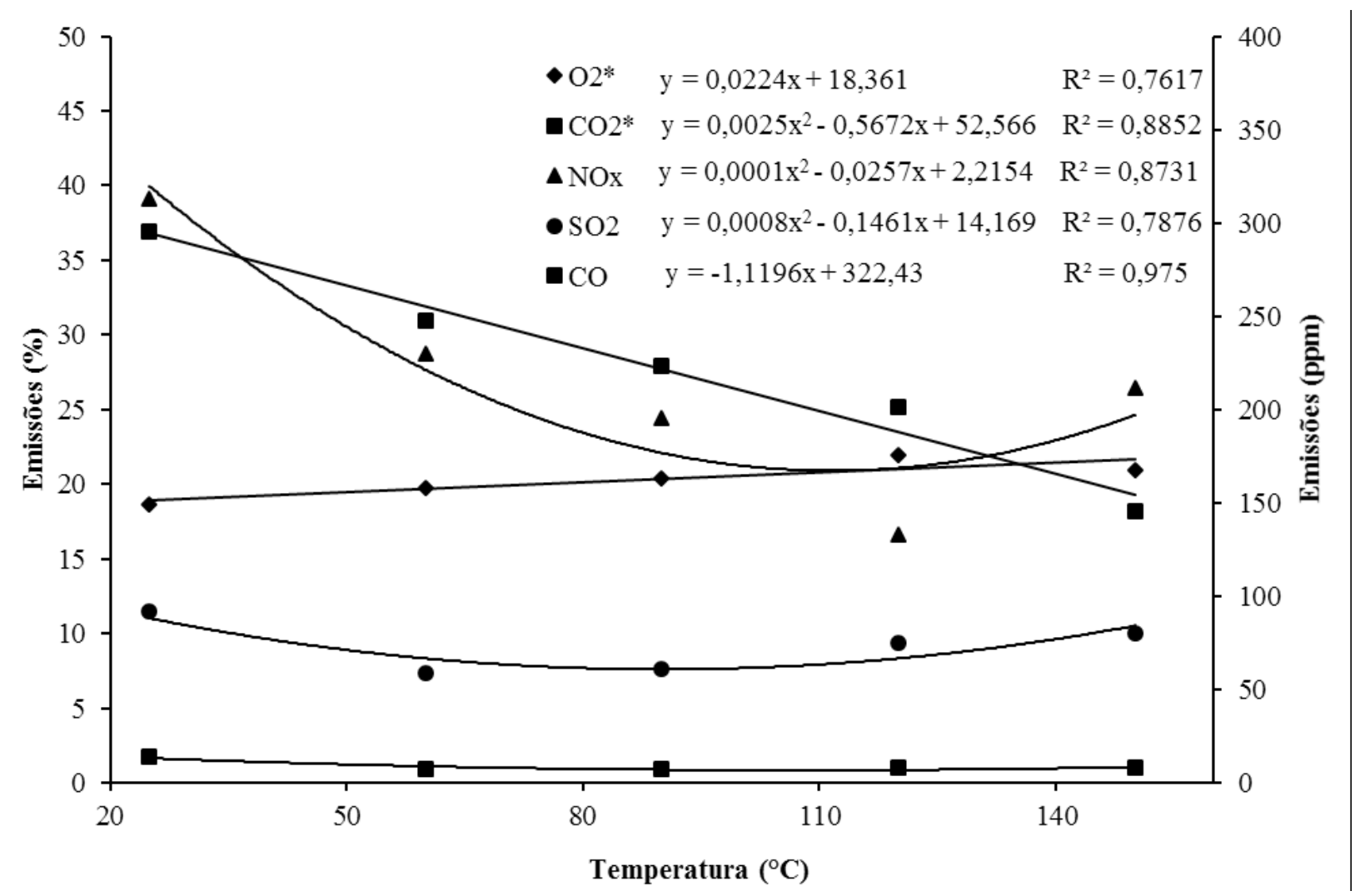

* Emissões de $\mathrm{O}_{2}$ e $\mathrm{CO}_{2}$ são apresentadas em \%.

Figura 3. Emissão dos gases em função das diferentes temperaturas de injeção do óleo vegetal.

encontrando-se o seu menor valor na temperatura do óleo vegetal de $91,3{ }^{\circ} \mathrm{C}$.

Os níveis de $\mathrm{NO}_{\mathrm{x}}$ decresceram à medida em que houve aumento na temperatura, apresentando os menores índices na temperatura do óleo vegetal de $128^{\circ} \mathrm{C}$, voltando a elevar-se com o incremento na temperatura, conforme apresentado na Figura 3. Pode-se verificar que, a partir de $128^{\circ} \mathrm{C}$, com o aumento da temperatura de injeção do óleo, voltou a elevar o índice de oxidação do nitrogênio do ar ambiente que entra na câmara de combustão, estas maiores temperaturas na câmara de combustão potencializaram a formação de óxidos de nitrogênio, conforme Mazieiro et al. (2005).

As cargas aplicadas no motor influenciaram significativamente as emissões de óxidos de nitrogênio $\left(\mathrm{NO}_{\mathrm{x}}\right)$, óxidos de enxofre $\left(\mathrm{SO}_{2}\right)$ e monóxido de carbono (CO), conforme apresentado na Figura 4.

Verificou-se que, com o aumento da carga aplicada no motor, as emissões de $\mathrm{SO}_{2}$ se elevaram, conforme apresentado na Figura 4, isso devido a maior demanda de combustível. Também foi verificado o aumento nas emissões de $\mathrm{NO}_{x}$ a medida em que se aumentou a carga, apresentando valor máximo na demanda de carga de, aproximadamente, $1100 \mathrm{~W}$, reduzindo a partir desse valor. O monóxido de carbono apresentou queda nas emissões com a elevação da carga, apresentando menor valor, próximo a $1200 \mathrm{~W}, \log 0$ em seguida, as concentrações de CO apresentaram elevação.

$\mathrm{O}$ fato da redução do $\mathrm{CO}$ ser verificada com a elevação da carga pode ser justificado pela dificuldade de pulverização do óleo vegetal pelos bicos injetores, visto que a maior demanda de carga exigiu uma maior quantidade de combustível, logo houve redução na eficiência de combustão. Resultados semelhantes foram encontrado por Silva et al. (2003), evidenciando a queda na eficiência de combustão devido a dificuldade de pulverização do combustível na câmara de combustão em virtude de sua elevada viscosidade. 


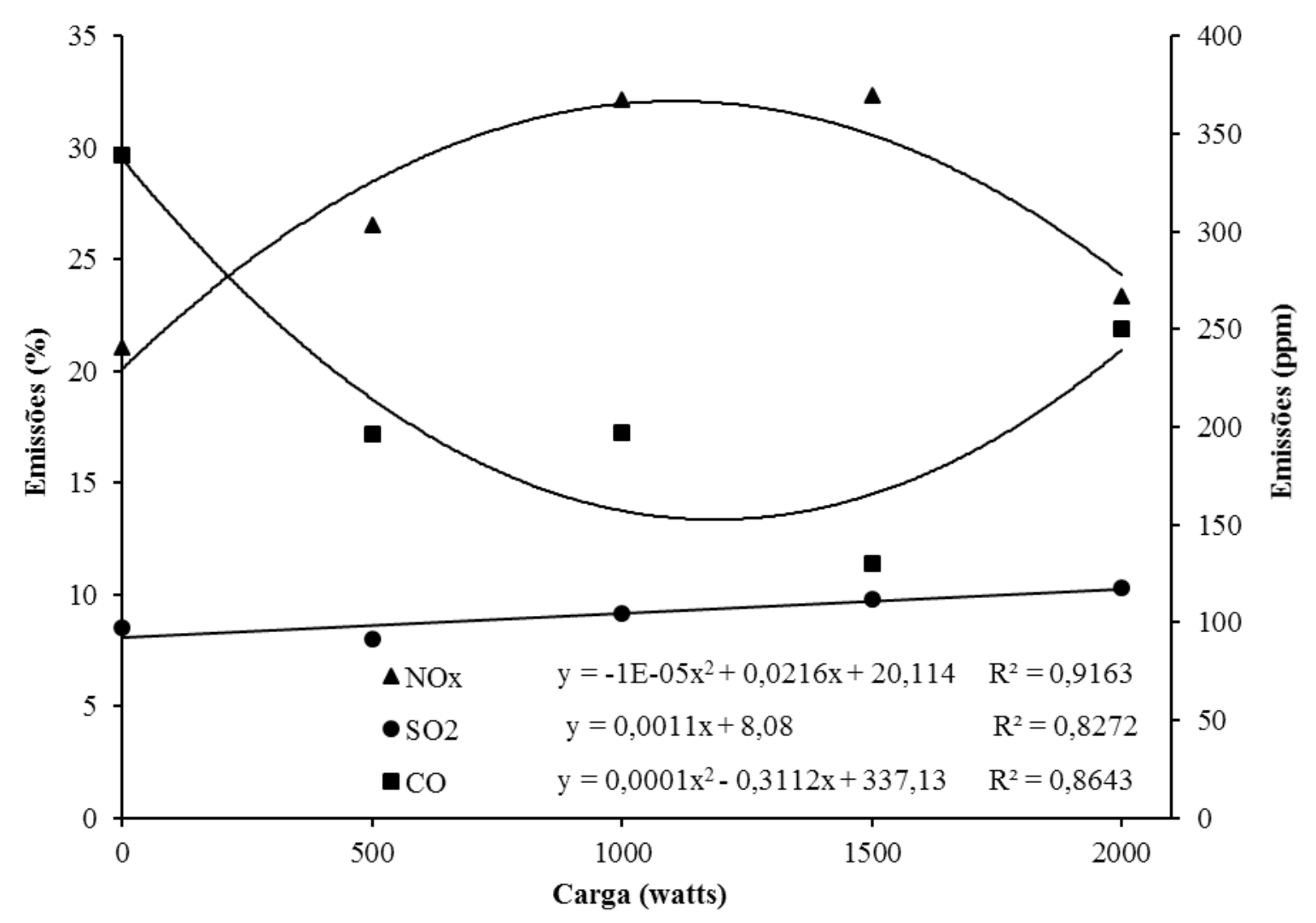

* Emissões de $\mathrm{CO}_{2}$ são apresentadas em \%.

Figura 4. Emissão dos gases em função das cargas aplicadas no motor.

Menores concentrações de $\mathrm{NO}_{\mathrm{x}}$ à temperatura ambiente não justificam sua utilização nesta temperatura, visto que a viscosidade do óleo a esta temperatura é muito elevada, podendo gerar danos ao motor, conforme apresentado por Pimentel e Belchior (2002) e Mazieiro et al. (2007).

Observou-se que o aumento da carga aplicada e a elevação da temperatura de injeção proporcionaram aumento significativo no consumo horário, conforme apresentado na Figura 5.

Os resultados mostraram que na faixa de temperatura analisada, a cada aumento de $500 \mathrm{~W}$ na demanda de carga, o consumo elevou-se em média de $29 \%$, sendo que os maiores valores de consumo ocorreram quando a demanda foi de 2000 W, condição que propiciou elevação em torno de $174 \%$ no consumo, quando comparado ao consumo do gerador trabalhando sem carga (Figura 5).

O aumento do consumo de combustível está relacionado ao acréscimo na demanda de carga, ocasionando maior consumo para os maiores valores de carga solicitada. Dados semelhantes foram encontrados por Nascimento et al. (1999), que ao alimentar um grupo gerador de $75 \mathrm{kVA}$ $(60 \mathrm{~kW})$ com óleo de dendê in natura, adaptando um sistema de pré-aquecimento do óleo e um sistema de alternância de combustível, observaram o aumento de 15 a $20 \%$ no consumo específico, dependendo da força aplicada.

Quando analisado o acréscimo de temperatura de injeção do óleo, verificou-se que a cada faixa de carga analisada, houve variação no acréscimo de consumo entre uma temperatura e a próxima utilizada. $\mathrm{O}$ aquecimento do óleo a temperatura ambiente de $25^{\circ} \mathrm{C}$ para $60^{\circ} \mathrm{C}$ ocorreu aumento em média de $2 \%$ no consumo de combustível, conforme apresentado na Figura 5. O maior consumo ocorreu nas maiores temperaturas, quando houve $6,8 \%$ de elevação no consumo quando comparado ao consumo do óleo sob temperatura ambiente e sob temperatura de $150^{\circ} \mathrm{C}$.

$\mathrm{O}$ incremento no consumo de combustível 


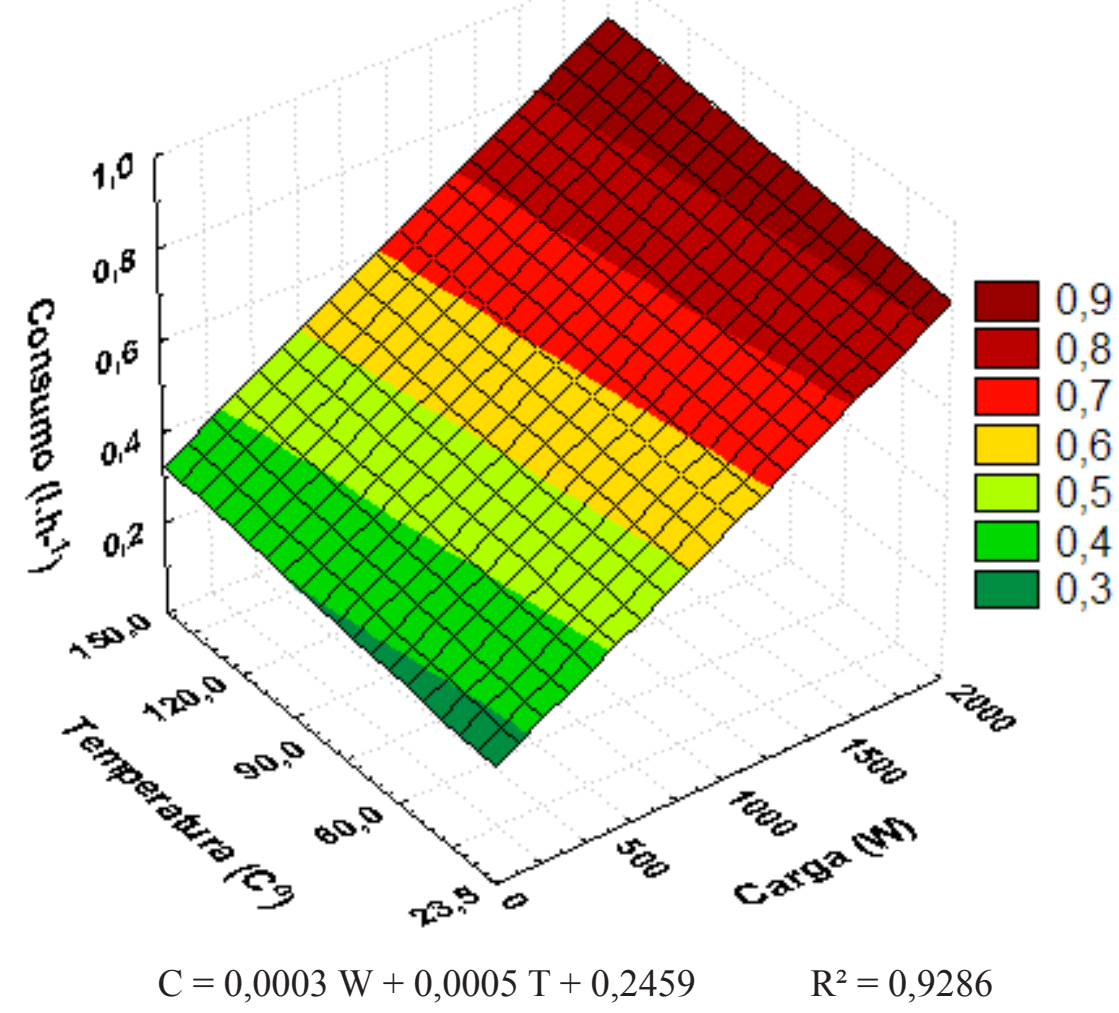

Figura 5. Consumo horário de combustível em função da carga demandada e temperatura de injeção do óleo vegetal.

ocorreu devido à redução da viscosidade do óleo com o aumento da temperatura do óleo vegetal injetado, proporcionando, assim, maior facilidade de pulverização dos bicos injetores do motor, conforme verificado por Soares et al. (2001) que, ao avaliarem o desempenho de um motor diesel alimentado com óleo de dendê, verificaram que a viscosidade afetou a qualidade da pulverização do combustível pelos bicos injetores e, quando aquecido a $55^{\circ} \mathrm{C}$, ocorreu acréscimo de $15 \%$ no consumo. Entretanto, quando o óleo foi aquecido a 80 e $100^{\circ} \mathrm{C}$, o consumo decresceu e foi semelhante ao consumo do diesel, condição que proporcionou problemas de vedação interna para os bicos injetores, ocasionados, possivelmente, pela oxidação do óleo e formação de gomas, ou pela danificação do filtro de combustível, quando aquecido a $100^{\circ} \mathrm{C}$.

\section{CONCLUSÕES}

- O aquecimento do óleo vegetal de soja aos $91,3^{\circ} \mathrm{C}$ apresentou o menor índice de emissão de $\mathrm{SO}_{2}$;

- A carga de $1100 \mathrm{~W}$ apresentou valor máximo de emissão $\mathrm{NO}_{\mathrm{x}}$ e mínimos de $\mathrm{CO}$ e o aumento da carga proporcionou aumento nos níveis de emissão de $\mathrm{SO}_{2}$;

- O consumo horário do motor com o uso de óleo vegetal de soja pré-aquecido aumentou com o incremento da temperatura de aquecimento e carga demandada.

\section{REFERÊNCIAS BIBLIOGRÁFICAS}

ANP-AGÊNCIANACIONALDO PETRÓLEO, GÁS NATURAL E BIOCOMBUSTÍVEIS. Cartilha do Posto Revendedor de Combustíveis / Agência Nacional do Petróleo, Gás Natural e Biocombustíveis. $4^{\text {a }}$ Edição - Rio de Janeiro: ANP, 2009.

ANP-AGÊNCIANACIONALDO PETRÓLEO,

\section{2


GÁS NATURAL E BIOCOMBUSTÍVEIS. Anuário Estatístico Brasileiro do Petróleo, Gás Natural e Biocombustíveis. Rio de Janeiro: ANP, 2013.

BARBOSA, R.L.; SILVA, F.M.; SALVADOR, N.; VOLPATO, C.E.S. Desempenho comparativo de um motor de ciclo diesel utilizando diesel e misturas de biodiesel. Revista Ciência agrotecnologia, Lavras, v.32, n.5, p.1588-1593, 2008.

BÜTTNER, D. Carburantes de origen vegetal: el punto de vista del sector productor de motores. In: DELGADO, L.M. Los cultivos no alimentarios como alternativa al abandono de tierras. Madrid, España: Agricola Española, p.111-125, 1994.

CORREA, I.M.; MAZIEIRO, J.V.G.; UNGARO, M.R.; BERNADI, J.A.; STORINO, M. Desempenho de motor diesel com misturas de biodiesel de óleo de girassol. Revista Ciência e Agrotecnologia, v.32, p.923-928, 2008.

FERREIRA, D.F. Sisvar: a computer statiscal analysis system. Ciência e Agrotecnologia, v.35, n.6, p.1039-1042, 2011.

GRABOSKY, M.S., MCCORMICK, R.L. Combustion of fat and vegetable oil derived fuels in diesel engines. Progress in Energy Combustion Science, v.24, p.125-164, 1998.

INOUE, G.H. Uso do óleo vegetal em motor estacionário de ciclo diesel. 2008. 114f. Tese (Doutorado em Engenharia Agrícola).Universidade Federal de Viçosa, Viçosa, MG, 2008.

MACHADO, P.R.M. Avaliação de desempenho do óleo de soja como combustível para motores diesel. 212f. 2003. Dissertação (Mestrado em Engenharia Agrícola). Universidade Federal de Santa Maria, Santa Maria, RS. 2003.

MARTINI, J.; DELALIBERA, H.C.; NETO, P.H.W. Consumo de óleo de soja pré-aquecido por motor diesel. Revista Brasileira de Agrociência, v.18, n.2-4, p.213-220, 2012.
MAZIEIRO, J.V.G.; CORREAA, I.M.; TRIELLI, M.A.; BERNADINI, J.A.; AGOSTINI, M.D'. Avaliação de emissões poluentes de um motor de ingnição por compressão utilizando óleo diesel e éster etílico de óleo de girassol como combustível. In: CONGRESSO BRASILEIRO DE PLANTAS OLEAGINOSAS, ÓLEOS VEGETAIS E BIODIESEL, 2., 2005, Varginha. Anais... Varginha, MG: UFLA, 2005. p.723-728.

MAZIEIRO, J.V.G.; CORREA, I.M.; ÚNGARO, M.R., BERNARDI, J.A.; STORINO, M. Desempenho de um motor diesel com óleo bruto de girassol. Revista Brasileira de Agrociência, Pelotas, v.13, n.2, p.249-255, 2007.

MIALHE, L.G. Ensaio \& certificação de máquinas motoras. Máquinas agrícolas: ensaios \& certificação. Piracicaba: FEALQ, 1996. Cap.7, p.321-370.

MILHOR, C.E. Sistema de desenvolvimento para controle eletrônico dos motores de combustão interna do ciclo Otto. 2002. 86f. Dissertação (Mestrado em Engenharia Mecânica), Escola de Engenharia São Carlos/USP. São Carlos, SP. 2002.

MORAES, J.R. Manual dos óleos vegetais e suas possibilidades energéticas. CNI, 1980. 78p.

NASCIMENTO, M.V.G.; VIEIRA, L.S.R.; SILVA, M.R.; FLEURY, G.; DOMINGUES, P.C.; SADI, J.C.; ALMEIDA, S.C.A.; BELCHIOR, C.R.P. Opções à geração diesel-elétrica para sistemas isolados na Região Norte: Eólica, Hidrocinética e Biomassa. In: Iguaçu-PR 1999. SNTPEE, 15. Foz do

RABELO, I.D.; HATAKEYAMA, K.; CRUZ, C.M.G.S. Estudo de desempenho de combustíveis convencionais associados a biodiesel obtido pela transesterificação de óleo usado em fritura. Revista Educação \& Tecnologia, UTFPR - Curitiba, n.8. 2011.

SCHLOSSER, J.F.; MACHADO, P.R.M.; CAMARGO, M.N. Desempenho de misturas pré-aquecidas de óleo de soja cru e diesel como 
combustível para motores agrícolas. Ciência Rural, Santa Maria, v.37, n.5, p.1329-1335, 2007.

SILVA, M.; ESCUER, M.; DESSAI, P.; GÓNGORA, E.; SOUSA, F.; SENOS, M.L.; GASPAR, J.L. Avaliação de emissões poluentes de um motor diesel. Simpósio de Engenharia, 3, Encontro Luso-Espanhol de Meteorologia, 4. Anais... Universidade de Aveiro, 2003.

SOARES, F.G.; VIEIRA, L.S.R.; NASCIMENTO, M.V.G. Avaliação prática do emprego de óleos vegetais "in natura" em substituição ao diesel em grupos geradores. In: Seminário Nacional de Produção e Transmissão de Energia elétrica, 16. Anais... Campinas, 2001.

STATSOFT. Statistica 7.0 Software. Tucksa, USA, 2005.

TOMAZZONI, G.; QUINTELLA, C.M.; PEPE, I.M.; MEIRA, M.; OKAMURA, L.A.; NETO, P.R.C. Prospecção do uso de clorofila como parâmetro de diferenciação da adição de óleo vegetal ao diesel em vez de biodiesel. Cadernos de Prospecção, v.6, n.2, p.199-207. 2013. 